\title{
Green and Fast Synthesis of 2-Arylidene-indan-1,3-diones Using a Task-Specific Ionic Liquid
}

\author{
Abdolhamid Alizadeh,* Zahra Beiranvand, Zahra Safaei, Mohammad M. Khodaei, and Eveliina Repo
}

Cite This: ACS Omega 2020, 5, 28632-28636

Read Online

ABSTRACT: A novel method for condensation reaction of indan1,3-dione with various aldehydes which are efficiently catalyzed by a task-specific ionic liquid, 2-hydroxyethylammonium formate, to provide the corresponding 2-arylidenindane-1,3-diones has been developed. This green, low-cost, high-yield, and fast reaction takes place at room temperature without the use of any solvent and catalyst. A plausible reaction mechanism that involves ionic liquidassisted activation is also discussed. This work is the first report of ionic liquids as a reaction medium and catalyst for the synthesis of 2-arylidenindane-1,3-diones.

\section{INTRODUCTION}

2-Arylidenindane-1,3-diones are an important class of chemicals with many potential applications ranging from material to medical science. Some derivatives show antibacterial activities and nonlinear optical properties, and some have been used as electroluminescent devices, eye lens clarification agents, ${ }^{1}$ urease and protease inhibitors, and anticoagulant agents and alleviate symptoms of diabetes. ${ }^{2-4}$ They can be also considered as organic Lewis acids. ${ }^{5,6}$ Because of their low-lying lower unoccupied molecular orbitals, they are reactive Michael acceptors and have been used as heterodienes in cycloaddition reactions. $^{7,8}$

Synthesis of 2-arylideneindane-1,3-diones through condensation reaction of indan-1,3-dione with aromatic aldehydes using piperidinein in organic solvents, ${ }^{8}$ pyridine, ${ }^{2}$ and aqueous sodium hydroxide 9 has been reported. In addition, various amino acids and amines have been employed for synthesis of 2arylidenindane-1,3-diones starting from aromatic aldehydes and indan-1,3-dione. ${ }^{10}$ Also, the microwave technique (250 watt, $150{ }^{\circ} \mathrm{C}$ ) in water has been utilized to obtain 2arylidenindane-1,3-diones. ${ }^{11}$ In addition, synthesis of 2arilydeneindan-1,3-diones in the presence of calcium oxide, ${ }^{12}$ magnesium oxide or silica gel, ${ }^{13}$ and zirconium $^{4}$ has been reported. Nevertheless, the reported methods have some flaws, namely, usage of costly reagents and toxic solvents, time- and resource-wasting procedures, poor yields, and harsh reaction conditions. Thus, a facile and green method for synthesis of 2arylidenindan-1,3-diones is still challenging and necessary. Ionic liquids (ILs) have attracted a great deal of interest for organic transformations ${ }^{14}$ because of high ionic conductivity, solubility of different materials, and thermal, mechanical, chemical, and electrochemical stabilities. ${ }^{15}$ Unique properties of ILs such as low toxicity, nonflammability, nonvolatility, and

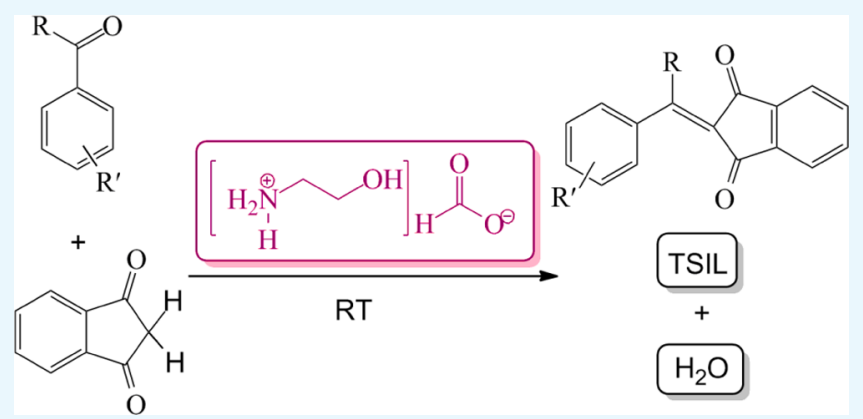

ease of handling make them green media for organic synthesis. ${ }^{16}$ Inspired by the previous report of our group, ${ }^{17}$ we sought to rational design of a reaction for synthesis of 2arylidenindan-1,3-diones by the IL. On this subject, in this study, a low-cost and task-specific IL, namely, 2-hydroxyethylammonium formate (2-HEAF), ${ }^{18}$ has been reported to form 2 -arylidenindan-1,3-dione derivatives. To our knowledge, there is no report describing the synthesis of 2-arylidenindan-1,3diones using ILs. 2-HEAF with unique properties, such as high conductivity, high solvation power, low melting point, and easy fabrication from inexpensive resources, is a very promising high-performance task-specific room temperature IL. Also, this method is the fastest reported so far for condensation reaction between aromatic aldehydes and indan-1,3-dione.

\section{RESULTS AND DISCUSSION}

We started our investigation by considering indan-1,3-dione and benzaldehyde as model substrates. The progress of the reactions was checked with thin layer chromatography (TLC). Using $0.25 \mathrm{mmol}$ of benzaldehyde and $0.25 \mathrm{mmol}$ of indan1,3-dione even after $72 \mathrm{~h}$ of stirring neat without adding 2HEAF at room temperature, in ethanol at room temperature and also under reflux conditions, low yield was obtained (Table 1, entries 1-3). Accordingly, we carried out the reaction in the presence of $2-\mathrm{HEAF}$ as an IL. Upon the

Received: July 29, 2020

Accepted: October 8, 2020

Published: October 28, 2020 
Table 1. Synthesis of 2-Arylidenindan-1,3-dione by the Reaction of Indan-1,3-dione with Benzaldehyde under Various Conditions in the Presence of 2-HEAF ${ }^{a}$

$\begin{array}{cccccc}\text { entry } & \text { 2-HEAF }(\mathrm{mmol}) & \text { solvent } & \text { temp. }\left({ }^{\circ} \mathrm{C}\right) & \text { time } & \text { yield }(\%)^{b} \\ 1 & 0.0 & & \text { r.t. } & 72 \mathrm{~h} & 25 \\ 2 & 0.0 & \mathrm{EtOH} & \text { r.t. } & 24 \mathrm{~h} & 25 \\ 3 & 0.0 & \mathrm{EtOH} & \text { reflux } & 24 \mathrm{~h} & 25 \\ 4 & 11.2 & & \text { r.t. } & 1 \mathrm{~min} & 80 \\ 5 & 5.6 & & \text { r.t. } & 1 \mathrm{~min} & 80 \\ 6 & 1.1 & & \text { r.t. } & 1 \mathrm{~min} & 85 \\ 7 & 0.1 & & \text { r.t. } & 1 \mathrm{~min} & 98\end{array}$

${ }^{a}$ Reaction conditions: benzaldehyde $(0.25 \mathrm{mmol})$, indan-1,3-dione $(0.25 \mathrm{mmol})$, and 2-HEAF. ${ }^{b}$ Yields refer to the pure isolated products.

addition of $1 \mathrm{~mL}$ of 2-HEAF, condensation immediately occurred and the reaction led to the desired product straightaway after less than $1 \mathrm{~min}$ in $80 \%$ yield without using any solvent or catalyst at room temperature (Table 1, entry 4). Briefly, the addition of water to the reaction mixture resulted in an immediate precipitation of the final products, and further washing with distilled water led to the desired pure 2benzylidenindane-1,3-diones. The optimum amount of 2HEAF was examined by the comparison of four different volumes $(1,0.5,0.1$, and $0.01 \mathrm{~mL})$ which equals $\sim 11.2,5.6$, 1.1 , and $0.1 \mathrm{mmol}$, respectively $\left(M_{\mathrm{w}}=107.11 \mathrm{~g} / \mathrm{mol}\right.$; density = $\left.1.204 \mathrm{~g} / \mathrm{cm}^{3}\right)$, in this reaction. ${ }^{17}$ In these cases, the desired arylidenindane-1,3-dione was formed in $80,80,85$, and $98 \%$ isolated yields after $1 \mathrm{~min}$ (Table 1 , entries 4-7). In the presence of $0.01 \mathrm{~mL}$ of 2 -HEAF, the desired product in $98 \%$ yield (monitored by TLC) was isolated, and therefore, we decided to use this minimum amount for the reaction. Among the various conditions, the neat condition was found to be the most convenient, affording the desired 2-benzylidenindane-1,3diones in excellent yields at room temperature and in short reaction times. Full synthetic details are reported in the Experimental Section. The lack of the formation of the product in the absence of 2-HEAF reveals the crucial catalytic role of this IL to produce 2-arylidenindane-1,3-diones. Additional experiments were carried out to examine the influence of other ILs through some experiments. Among various ILs tested, [tetra- $n$-butylphosphonium-bromide (TBB), diethanolammonium formate (Di-Fo), diethanolammonium acrylate (DiAcryl), and diethanolammonium acetate (Di-Ac)] gave poor to moderate yields of the corresponding product (Table 2, entries $1-5)$. Therefore, it was concluded that 2-HEAF was the best within the five ILs used in this study. To extend the scope of this method, the reaction was further investigated with various

Table 2. Catalytic Effect of Some ILs on Synthesis of 2Arylidenindan-1,3-dione by the Reaction of Indan-1,3-dione with Benzaldehyde ${ }^{a}$

$\begin{array}{clccc}\text { entry } & \text { TSIL } & \text { IL }(\mathrm{mL}) & \text { time } & \text { yield }(\%)^{b} \\ 1 & \text { TBB } & 1 & 48 \mathrm{~h} & 25 \\ 2 & \text { Di-Fo } & 1 & 5 \mathrm{~min} & 25 \\ 3 & \text { Di-Ac } & 1 & 5 \mathrm{~min} & 75 \\ 4 & \text { Di-Acryl } & 1 & 10 \mathrm{~min} & 80 \\ 5 & \text { 2-HEAF } & 1 & 1 \mathrm{~min} & 98\end{array}$

${ }^{a}$ Reaction conditions: benzaldehyde $(0.25 \mathrm{mmol})$, indan- 1,3 dione $(0.25 \mathrm{mmol})$, and 2-HEAF at room temperature. ${ }^{b}$ Yields refer to the pure isolated products. aryl and heteroaryl aldehydes to afford the corresponding products, and the results are summarized in Table 3. To the best of our knowledge, synthesized derivatives 15 and 17 are new.

Table 3. Synthesis of 2-Arylidenindane-1,3-diones Promoted by 2 -HEAF

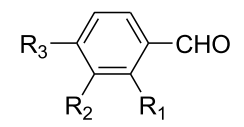

\begin{tabular}{llll} 
entry & \multicolumn{1}{c}{ aldehyde } & yield $\%$ & $\mathrm{mp}\left({ }^{\circ} \mathrm{C}\right)$ \\
1 & $\mathrm{R}_{1}, \mathrm{R}_{2}, \mathrm{R}_{3}=\mathrm{H}$ & 98 & 150 \\
2 & $\mathrm{R}_{1}, \mathrm{R}_{2}=\mathrm{H} ; \mathrm{R}_{3}=\mathrm{CH}_{3}$ & 98 & $150-152$ \\
3 & $\mathrm{R}_{1}, \mathrm{R}_{2}=\mathrm{H} ; \mathrm{R}_{3}=\mathrm{OCH}_{3}$ & 98 & 159 \\
4 & $\mathrm{R}_{1}, \mathrm{R}_{2}=\mathrm{H} ; \mathrm{R}_{3}=\mathrm{NO}_{2}$ & 98 & $230-232$ \\
5 & $\mathrm{R}_{1}=\mathrm{OCH}_{3} ; \mathrm{R}_{2}, \mathrm{R}_{3}=\mathrm{H}$ & 85 & 168 \\
6 & $\mathrm{R}_{1}, \mathrm{R}_{2}=\mathrm{OCH}_{3} ; \mathrm{R}_{3}=\mathrm{H}$ & 98 & 159 \\
7 & $\mathrm{R}_{1}, \mathrm{R}_{3}=\mathrm{OCH}_{3} ; \mathrm{R}_{2}=\mathrm{H}$ & 98 & 204 \\
8 & $\mathrm{R}_{1}, \mathrm{R}_{3}=\mathrm{H} ; \mathrm{R}_{2}=\mathrm{NO}_{2}$ & 98 & $251-252$ \\
9 & $\mathrm{R}_{1}, \mathrm{R}_{2}=\mathrm{H} ; \mathrm{R}_{3}=\mathrm{Cl}_{1}$ & 98 & 178 \\
10 & $\mathrm{R}_{1}, \mathrm{R}_{3}=\mathrm{Cl} ; \mathrm{R}_{2}=\mathrm{H}$ & 98 & 194 \\
11 & 4-(dimethylamino)-benzaldehyde & 98 & $169-170$ \\
12 & 5-methyl-2-furaldehyde & 98 & $176-178$ \\
13 & 2-thiophencarboxaldehyde & 98 & 175 \\
14 & 1-naphthaldehyde & 90 & $238-240$ \\
15 & biphenyl-4-carbaldehyde & 98 & $252-253$ \\
16 & 4-(dimethylamino)-cinnammaldehyde & 60 & $104-106$ \\
17 & 4-(12-bromododecyloxy) benzaldehyde & &
\end{tabular}

Based on our previous work, ${ }^{17}$ a step-by-step mechanism has been proposed for the IL-catalyzed condensation reaction of aromatic aldehydes with indan-1,3-dione, as outlined in Scheme 1 .

In the next step, the protonated aldehydes may undergo a nucleophilic attack by these nucleophilic intermediates, which affords alcohols. It important to point out that if acidic protons are available (with the protic solvent or catalyst), alcohols tend to remove water to generate 2-benzylidene-indan-1,3-diones. It is worth noting that no alcohols (monitored by TLC) were detected in this reaction and only 2-arylidenindane-1,3-diones in quantitative yield were obtained. 2-HEAF was recovered, and water was detected as the only byproduct of the reactions. We believe that the described reaction proceeds through a onepot consecutive pathway affected by dual catalytic roles of 2HEAF as a task-specific IL. As can be seen, the protonated carbonyl moiety of the aldehydes can be easily generated by means of the acidic fragment of 2-HEAF, implying that ethanol amine might serve as a base and therefore deprotonate $\mathrm{C}-\mathrm{H}$ acids (indan-1,3-dione), giving active enolate.

Extending the study further, we decided to perform the reaction in the presence of an excess amount of indan-1,3dione to investigate if it was able to provide Michael adducts. For this purpose, as a pilot experiment, a mixture of indan-1,3dione and benzaldehye (ratio 2:1) in $0.01 \mathrm{~mL}$ IL was stirred, the reaction was terminated after a certain time monitored by TLC, and the purified product was yielded after workup. Remarkably, even in the presence of an excess amount of indan-1,3-dione, only 2-arylidenindan-1,3-dione was observed and Michael adducts were not identified (monitored by TLC). Besides this, to prove the efficacy of the IL, the synthesis of 2arylidenindan-1,3-dione in the presence of 2-HEAF was 
Scheme 1. Proposed Mechanism for the Formation of 2Arylidenindan-1,3-diones in the Presence of 2-HEAF (IL)

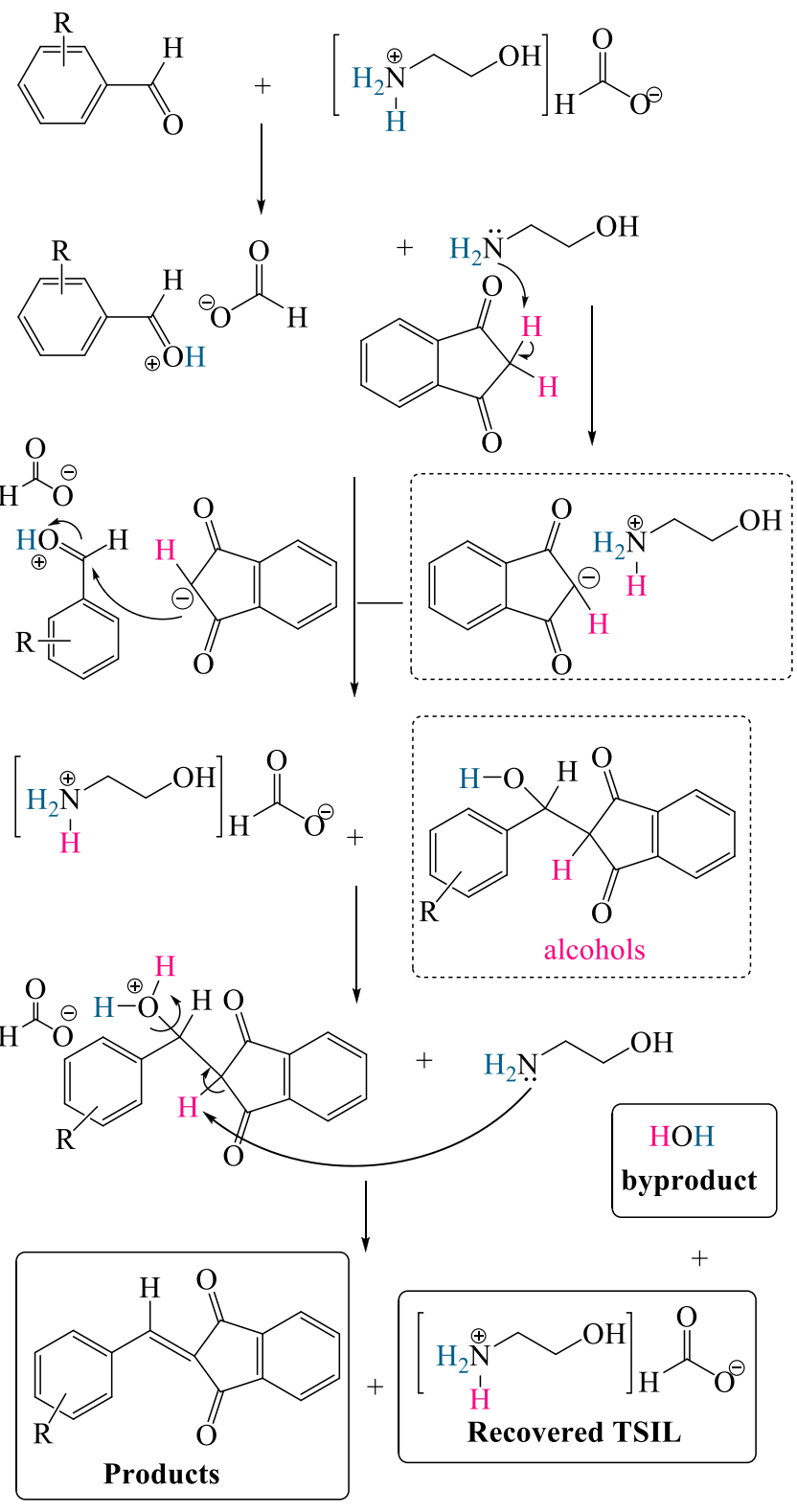

compared with some of the previously reported methods (Table 4).

\section{CONCLUSIONS}

In general, 2-arylidenindan-1,3-dione derivatives are used as important intermediates in organic synthesis, and thus, a simple, green, and efficient protocol for their synthesis is

Table 4. Comparison between Our Results for the Synthesis of Arylidenindane-1,3-diones and Other Reported Methods

\begin{tabular}{cclcc}
\hline entry & \multicolumn{1}{c}{ reactants } & \multicolumn{1}{c}{ conditions } & time/min & $\begin{array}{c}\text { yield } \\
(\%)^{\text {ref }}\end{array}$ \\
\hline 1 & 4-chlorobenzaldehyde & piperidine/reflux & 180 & $87^{19}$ \\
2 & 4-chlorobenzaldehyde & MgO/grinding & 20 & $92^{13}$ \\
3 & 4-chlorobenzaldehyde & silicagel/grinding & 20 & $95^{13}$ \\
4 & 4-chlorobenzaldehyde & $\mathrm{CaO}$ & 10 & $67^{12}$ \\
5 & 4-chlorobenzaldehyde & TSIL/r.t. & 1 & 98
\end{tabular}

essential. The present procedure that involves the use of a simply made and inexpensive ammonium-based IL provides a novel protocol for the generation of a library of diversely substituted 2-benzylidene-indan-1,3-diones under neat conditions at room temperature in high yields. Attractive features such as an eco-friendly, environmentally friendly, and simple procedure combined with the ease of workup make this method economic, benign, and a waste-free chemical process. We also, encountered a remarkable acceleration in the rate of a reaction with the use of this IL. This novel method opens up a new access to this group of compounds (Scheme 2).

Scheme 2. Formation of 2-Arylidenindan-1,3-dione in the Presence of an Excess Amount of Indan-1,3-dione

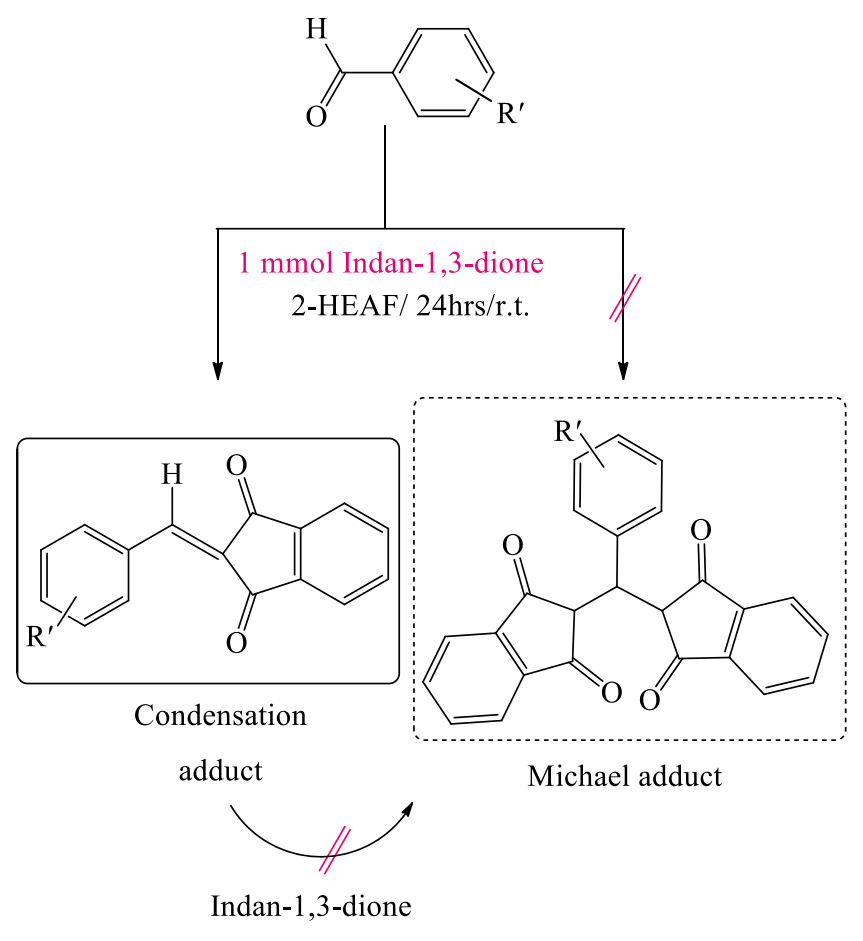

\section{EXPERIMENTAL SECTION}

Ethanolamine, formic acid, indan-1,3-dione, aldehydes, and 12dibromododecane were all reagent-grade materials and used without further purification. Throughout all experiments, distilled water was used, and all the experiments were carried out at room temperature. ${ }^{1} \mathrm{H}$ NMR spectra were recorded on a $200 \mathrm{MHz}$ spectrometer in deuteriochloroform solution and are reported in parts per million with respect to the chloroform peak at $7.26 \mathrm{ppm} .{ }^{13} \mathrm{C}$ NMR spectra were recorded on a 200 $\mathrm{MHz}$ spectrometer in deuteriochloroform solution and are reported in parts per million with respect to the chloroform peak at 77.0. The units of the coupling constants $(J)$ are given in Hz. Melting points are uncorrected. Fourier transform infrared spectra were recorded using a drop casting technique on $\mathrm{KBr}$ plates and are reported in wavenumbers $\left(\mathrm{cm}^{-1}\right)$.

General Procedure for the Synthesis of 2-Arylidenindane-1,3-diones. (Representative procedure for synthesis of 2-benzylidene- $1 \mathrm{H}$-indene-1,3-( $2 H)$-dione). In a reaction vial (in a round bottom glass test tube), benzaldehyde (0.106 g, $0.25 \mathrm{mmol})$, indan-1,3-dione $(0.036 \mathrm{~g}, 0.25 \mathrm{mmol})$, and 2HEAF $(0.1 \mathrm{mmol})$ were mixed together and stirred for $1 \mathrm{~min}$ at room temperature until completion (TLC) of the reaction. 
Then, the addition of water $(5 \mathrm{~mL})$ led to the immediate formation of the pure product of 2-benzylidene- $1 H$-indene-1,3$(2 \mathrm{H})$-dione $(0.230 \mathrm{~g}, 98 \%)$. The precipitated condensation product was filtered off and washed with water to afford the desired adducts. After completion of the reaction, water was removed via rotary evaporation, and the remaining IL was rinsed with ethyl acetate. In the following cycles $(2,3, \ldots)$ a small portion of the fresh IL was added each time to compensate the loss of IL and reach its optimized amount (0.1 $\mathrm{mmol}$ ). This procedure was followed for all the reactions listed in Table 3.

General Procedure for the Synthesis of 4-(12Bromododecyloxy)-benzaldehyde. To a solution of 4hydroxybenzaldehyde $(2.0 \mathrm{~g}, 16.40 \mathrm{mmol})$ and $\mathrm{K}_{2} \mathrm{CO}_{3}(3.97 \mathrm{~g}$, $28.7 \mathrm{mmol}$ ) in $20 \mathrm{~mL}$ of acetone, 1,12-dibromododecane $(16.14 \mathrm{~g}, 49.2 \mathrm{mmol})$ in $5 \mathrm{~mL}$ of acetone was added dropwise at room temperature, and the resulting mixture was refluxed for $17 \mathrm{~h}$. The solvent was removed via rotary evaporation, and the residue was dissolved in $\mathrm{CH}_{2} \mathrm{Cl}_{2}(20 \mathrm{~mL})$ and washed several times with water. After drying over $\mathrm{MgSO}_{4}$, the solvent was evaporated, and the residue purified by column chromatography on silica gel, using a solvent gradient from hexane/ $\mathrm{CH}_{2} \mathrm{Cl}_{2}(2: 8, \mathrm{v} / \mathrm{v})$, afforded 4-(12-bromododecyloxy)benzaldehyde as a crystalline white solid $(5.58 \mathrm{~g}, 92 \%)$. IR $\nu_{\max }$ (KBr): 3112, 2910, 2780 (HCO), 1687 (CO), 1610-1450, $1210 \mathrm{~cm}^{-1}$. ${ }^{1} \mathrm{H}$ NMR $\left(600 \mathrm{MHz} ; \mathrm{CDCl}_{3}\right): \delta_{\mathrm{H}}(\mathrm{ppm}) 1.28-$ $1.45(\mathrm{~m}, 16 \mathrm{H}), 1.79-1.85(\mathrm{~m}, 4 \mathrm{H}), 3.39(\mathrm{t}, J=9.7 \mathrm{~Hz}, 2 \mathrm{H}$, $\left.\mathrm{CH}_{2} \mathrm{Br}\right), 4.01\left(\mathrm{t}, J=9.6 \mathrm{~Hz}, 2 \mathrm{H}, \mathrm{CH}_{2} \mathrm{O}\right), 6.98(\mathrm{~d}, J=12.5 \mathrm{~Hz}$, $2 \mathrm{H}, \mathrm{Ph}), 7.81(\mathrm{~d}, \mathrm{~J}=12.5 \mathrm{~Hz}, 2 \mathrm{H}, \mathrm{Ph}), 9.87(\mathrm{~s}, 1 \mathrm{H}, \mathrm{HC}=\mathrm{O})$. ${ }^{13} \mathrm{C}$ NMR (150 MHz; $\left.\mathrm{CDCl}_{3}\right): \delta_{\mathrm{C}}(\mathrm{ppm}) 26.1,28.3,28.9$, 29.2, 29.5, 29.6, 29.7, 33.0, 34.1, 68.5, 114.8, 129.9, 132.0, $164.3,190.6 ; \mathrm{m} / z$ : (EI) $369.9\left(\mathrm{M}^{+}, 22 \%\right), 289(9), 123(100)$, 83.9(45), 69(30). HRMS (EI): $m / z$ calcd for $\mathrm{C}_{19} \mathrm{H}_{29} \mathrm{BrO}_{2}$, 368.1351 ; found, 368.1358 .

2(3-(12-Bromododecyloxy)benzylidene)-1H-indene1,3(2H)-dione (Table 3, Entry 17). Pale-green powder, mp $104-106{ }^{\circ} \mathrm{C}$. IR $\nu_{\max }(\mathrm{KBr}) 2918,2850,1680,1579,1552$, 1271, 1207, 1178, $742 \mathrm{~cm}^{-1} .{ }^{1} \mathrm{H} \mathrm{NMR}\left(200 \mathrm{MHz} ; \mathrm{CDCl}_{3}\right): \delta_{\mathrm{H}}$ (ppm) $1.30-2.02\left(\mathrm{~m}, 20 \mathrm{H}, \mathrm{CH}_{2}\right), 3.42(\mathrm{t}, J=6.5 \mathrm{~Hz}, 2 \mathrm{H}$, $\left.\mathrm{CH}_{2} \mathrm{Br}\right), 4.08\left(\mathrm{t}, J=6.0 \mathrm{~Hz}, 2 \mathrm{H}, \mathrm{CH}_{2} \mathrm{O}\right), 7.01(\mathrm{~d}, J=8.5 \mathrm{~Hz}$, $2 \mathrm{H}, \mathrm{Ph}), 7.81-8.16\left(\mathrm{~m}, 5 \mathrm{H}, \mathrm{Ar}-\mathrm{H}, \mathrm{H}_{\text {vinyl }}\right), 7.99$ (d, $J=8.4 \mathrm{~Hz}$, $2 \mathrm{H}, \mathrm{Ph}) .{ }^{13} \mathrm{C} \mathrm{NMR}\left(50 \mathrm{MHz} ; \mathrm{CDCl}_{3}\right): \delta_{\mathrm{C}}(\mathrm{ppm}) 25.96,28.18$, 28.77, 29.06, 29.33-29.51 (t), 32.84, 34.04, 68.44, 111.97, $114.85,123.05,126.38,134.82,135.03,137.28,140,146.99$, 162.83, 163.77, 190.88. Mass 29, 41, 55, 165, 233, 249, 250, 496, 499.

2(Biphenyl-3-methylene)-1H-indene-1,3(2H)-dione (Table 3, Entry 15). Yellow powder, mp $238-240{ }^{\circ} \mathrm{C} .{ }^{1} \mathrm{H}$ NMR (200 $\left.\mathrm{MHz} ; \mathrm{CDCl}_{3}\right): \delta_{\mathrm{H}}(\mathrm{ppm}) 7.37-8.58(\mathrm{~m}, 14 \mathrm{H}, \mathrm{Ph}) .{ }^{13} \mathrm{C} \mathrm{NMR}$ $\left(50 \mathrm{MHz} ; \mathrm{CDCl}_{3}\right): \delta_{\mathrm{C}}(\mathrm{ppm}) 123.32,127.26,127.34,128.42$, $129,132.12,134.89,135.17,135.37,139.77,140.05,142.52$, 145.77, 146.43, 189.16, 190.38. Mass 77, 104, 233, 252, 309, 310.

\section{ASSOCIATED CONTENT}

\section{(3) Supporting Information}

The Supporting Information is available free of charge at https://pubs.acs.org/doi/10.1021/acsomega.0c03645.

${ }^{1} \mathrm{H}$ and ${ }^{13} \mathrm{C}$ NMR and mass spectra of the new synthesized products (PDF)

\section{AUTHOR INFORMATION}

\section{Corresponding Author}

Abdolhamid Alizadeh - Department of Organic Chemistry, Faculty of Chemistry, Razi University, Kermanshah 6714967346, Iran; Department of Separation Science, School of Engineering Science, LUT University, Lappeenranta 53850, Finland; 이이이.org/0000-0001-5247-015X; Email: ahalizadeh2@hotmail.com, abdolhamid.alizadeh@ lut.fi

\section{Authors}

Zahra Beiranvand - Department of Organic Chemistry, Faculty of Chemistry, Razi University, Kermanshah 6714967346, Iran

Zahra Safaei - Department of Separation Science, School of Engineering Science, LUT University, Lappeenranta 53850, Finland

Mohammad M. Khodaei - Department of Organic Chemistry, Faculty of Chemistry, Razi University, Kermanshah 6714967346, Iran

Eveliina Repo - Department of Separation Science, School of Engineering Science, LUT University, Lappeenranta 53850, Finland

Complete contact information is available at:

https://pubs.acs.org/10.1021/acsomega.0c03645

\section{Notes}

The authors declare no competing financial interest.

\section{ACKNOWLEDGMENTS}

The financial support of Razi University and Maa-ja vesitekniikan tuki ry (MVTT) to accomplish the project is appreciated.

\section{REFERENCES}

(1) (a) Salama, M. A.; Yousif, N. M.; Ahmed, F. H.; Hammam, A. G. Some reactions with 2 -arylidene-1,3-indandiones and related derivatives with antibacterial activities. Pol. J. Chem. 1988, 62, 243-250. (b) Afsah, E. M.; Etman, H. A.; Hamama, W. S.; Sayed-Ahmed, A. F. A study on the reaction of 1,3-indandione with Schiff bases: synthesis of new 1,3-indandiones with expected psychopharmacological and anticoagulant activity. Boll. Chim. Farm. 1998, 137, 244-248. (c) Osman, S. A. M.; Yousif, N. M.; Ahmed, F. H.; Hammam, A. G. Some reactions with 2-arylidene-1,3-indandiones for preparation of derivatives possessing antibacterial activity. Egypt. J. Chem. 1988, 31, 727-734. (d) Afsah, E. M.; Hammouda, M.; Zoorob, H.; Khalifa, M. M.; Zimaity, M. Introduction of some Pharmaceutically Active Heterocycles into the Benzylic moiety of 2-Benzyl-1,3-indandione. Pharmazie 1990, 45, 255-257. (e) Yoakim, C.; Hache, B.; Ogilvie, W.; O'Meara, J. A.; White, P. W.; Goudreau, N. Inhibitors of papilloma virus. WO2002050082A2, 2002; Chem. Abstr. 2002, 137, 63181. (f) Szymusiak, H.; Zieliński, R.; Domagalska, B. W.; Wilk, K. A. Electronic structure and nonlinear optical properties of model push-pull polyenes with modified indanone groups: a theoretical investigation. Comput. Chem. 2000, 24, 369-380. (g) Aziz, A. B. M. S. A.; Mohamed, E. S. Eur. Pat. Appl. 1992, 14 pp. CODEN: EPXXDW EP 489991 Al 19920617.

(2) Khan, G.; Aftab, M. F.; Bano, B.; Khan, K. M.; Murtaza, M.; Siddiqui, S.; Rehman, M. H.; Waraich, R. S. A New Indanedione Derivative Alleviates Symptoms of Diabetes by Modulating RAGENF-kappaB Pathway in db/db Mice. Biochem. Biophys. Res. Commun. 2018, 501, 863-870.

(3) (a) Bano, B.; Kanwal; Khan, K. M.; Begum, F.; Lodhi, M. A.; Salar, U.; Khalil, R.; Ul-Haq, Z.; Perveen, S. Benzylidine indane-1,3diones: As Novel Urease Inhibitors; Synthesis, in Vitro, and in Silico 
Studies. Bioorg. Chem. 2018, 81, 658-671. (b) Mitka, K.; Kowalski, P.; Pawelec, D.; Majka, Z. Synthesis of Novel Indane-1,3-dione Derivatives and Their Biological Evaluation as Anticoagulant Agents. Croat. Chem. Acta 2009, 82, 613-618.

(4) Oliveira, A. F. C. D. S.; de Souza, A. P. M.; de Oliveira, A. S.; da Silva, M. L.; de Oliveira, F. M.; Santos, E. G.; da Silva, I. E. P.; Ferreira, R. S.; Villela, F. S.; Martins, F. T.; Leal, D. H. S.; Vaz, B. G.; Teixeira, R. R.; de Paula, S. O. Zirconium catalyzed synthesis of 2arylidene Indan-1,3-diones and evaluation of their inhibitory activity against NS2B-NS3 WNV protease. Eur. J. Med. Chem. 2018, 149, 98109.

(5) (a) Cammi, R.; Ghio, C.; Tomasi, J. Neutral organic lewis acids of $\pi$ type. Int. J. Quantum Chem. 1986, 29, 527-539. (b) Liedl, E.; Wolschann, P. The reaction of activated nitrones to C-C-double bonds of organicLewis acids. OrganicLewis acids 37. Monatsh. Chem. 1982, 113, 1067-1071. (c) Goerner, H.; Leitich, J.; Polansky, O. E.; Riemer, W.; Ritter-Thomas, U.; Schlamann, B. Die Photoenolisierung, Autoxidation und Dimerisation von 2-Isobutyliden-1,3-indandion. Monatsh. Chem. 1980, 111, 309-329. (d) Margaretha, P. Die reaktion von Meldrumsäure mit isobutylidenmeldrumsäure : Ein reaktionskinetischer beitrag zur Michael-reaktion. Tetrahedron 1972, 28, 83-87. (f) Margaretha, P.; Polansky, O. E. Anbadons originating from organic bases and electrically neutral organic Lewis acids. Monatsh. Chem. 1969, 100, 576-583.

(6) Duan, J.; Cheng, J.; Li, B.; Qi, F.; Li, P. Enantioselective synthesis of spiro[1,3-indanedione-tetrahydrothiophene]s by organocatalytic Sulfa-Michael domino reaction. Eur. J. Org. Chem. 2015, 2015, 6130-6134.

(7) Lantaño, B.; Aguirre, J. M.; Drago, E. V.; Bollini, M.; Faba, D. J.; de la Faba, J. D. Synthesis of Benzylidenecycloalkan-1-ones and 1,5diketones under Claisen-Schmidt reaction: Influence of the temperature and electronic nature of arylaldehydes. Synth. Commun. 2017, 47, 2202-2214.

(8) (a) Trost, B. M. Comprehensive Organic Synthesis; Pergamon Press: Oxford, 1991; pp 341-394. (b) Inayama, S.; Mamoto, K.; Shibata, T.; Hirose, T. Structure and antitumor activity relation of 2arylidene-4-cyclopentene-1,3-diones and 2-arylideneindan-1,3-diones. J. Med. Chem. 1976, 19, 433-436.

(9) Tugrak, M.; Inci Gul, H.; Sakagami, H.; Gulcin, I.; Supuran, C. $\mathrm{T}$. New azafluorenones with cytotoxic and carbonic anhydrase inhibitory properties: 2-Aryl-4-(4-hydroxyphenyl)-5H-indeno[1,2-b]pyridin-5-ones. Bioorg. Chem. 2018, 81, 433-439.

(10) Ramachary, D. B.; Anebouselvy, K.; Chowdari, N. S.; Barbas, C. F. Direct organocatalytic asymmetric heterodomino reactions: The Knoevenagel/Diels-Alder/Epime sequence for the highly diastereoselective synthesis of symmetrical and nonsymmetrical synthons of benzoannelated centropolyquinanes. J. Org. Chem. 2004, 69, 58385849.

(11) Tu, S.-J.; Jiang, B.; Zhang, J.-Y.; Jia, R.-H.; Zhang, Y.; Yao, C.-S. Efficient and direct synthesis of poly-substituted indeni[1,2-b]quinolines assisted by p-toluene sulfonic acid using high-temperature water and microwave heating via one-pot, three-component reaction. Org. Biomol. Chem. 2006, 4, 3980-3985.

(12) Lu, Y.; Ren, Z.; Cao, W.; Tong, W.; Gao, M. Solvent-Free Synthesis of Ethyl $\alpha$-Cyanocinnamate in the Presence of $\mathrm{CaO}$. Synth. Commun. 2004, 34, 2047-2051.

(13) Wu, D.; Ren, Z.; Cao, W.; Tong, W. Solvent-Free Synthesis of 2-Arylideneindan-1,3-diones in the Presence of Magnesium Oxide or Silica Gel Under Grinding. Synth. Commun. 2005, 35, 3157-3162.

(14) (a) Cao, P.; Yuan, Y.; Huang, C.; Sun, W.; Zhao, L. Promoting the sulfuric acid catalyzed isobutane alkylation by quaternary ammonium ionic liquids. AIChE J. 2020, 66, No. e16979. (b) Zhang, X.; Li, H.; Li, X.; Liu, Y.; Li, X.; Guan, J.; Long, J. Glucose Aqueous Isomerization Catalyzed by Basic Ionic Liquids. ACS Sustainable Chem. Eng. 2019, 7, 13247-13256. (c) Wang, A.; Zhu, X.; Yin, H.; Fu, Y.; Hou, X. Chlorination of Toluene to oChlorotoluene Catalyzed by Ionic Liquids. Catalysts 2018, 8, 532547. (d) Tong, J.; Li, Y.-W.; Xu, D.-Z. Solvent-Controlled FriedelCrafts Reaction for the Synthesis of 3-Indolyl-3-hydroxy Oxindoles and 3,3-Diindolyl Oxindoles Catalyzed by Dabco-Base Ionic Liquids. Chemistry Select 2017, 2, 3799-3803. (e) Wang, S.; Liu, L.; Jiang, Y.; Hu, M.; Li, S.; Zhai, Q. Enzymatic Polymerization of Phenols Catalyzed by Chloroperoxidase in the Presence of Ionic Liquids/ Quaternary Ammonium Salts. Chem. J. Chin. Univ. 2016, 37, 17331739. (f) Li, L.; Liu, Y.; Yu, S.-T.; Liu, S.-W.; Xie, C.-X.; Liu, F.-S. Hydration of Alpha-Pinene Homogenous Catalyzed by Acidic Polyether-Modified Ammonium Salt Ionic Liquid in "Microreactor". Res. Chem. Intermed. 2015, 41, 2407-2414. (g) Zhang, J.; Zhang, Y.; Zhou, Z. Hydroxyl Ammonium Ionic Liquid-Catalyzed Simple and Efficient Synthesis of 5-arylidene-2,4thiazolidinediones under SolventFree Conditions. Green Chem. Lett. Rev. 2014, 7, 90-94. (h) Zhang, B.-H.; He, J.-Y.; Liu, S.-J.; Shi, L.-X. Asymmetric Aldol Reactions in Caprolactam-Quaternary Ammonium Salt Coordination Ionic Liquid Catalyzed by L-Pro-L-Trp. Helv. Chim. Acta 2013, 96, 1266-1268. (i) Ghosh, S. K.; Qiao, Y.; Ni, B.; Headley, A. D. Asymmetric Michael reactions catalyzed by a highly efficient and recyclable quaternary ammonium ionic liquid-supported organocatalyst in aqueous media. Org. Biomol. Chem. 2013, 11, 1801-1804.

(15) (a) Singh, S. K.; Savoy, A. W. Ionic liquids synthesis and applications: An overview. J. Mol. Liq 2020, 297, 112038. (b) Wang, B.; Qin, L.; Mu, T.; Xue, Z.; Gao, G. Are ionic liquids chemically stable? Chem. Rev. 2017, 117, 7113-7131. (c) Dong, K.; Liu, X.; Dong, H.; Zhang, X.; Zhang, S. Multiscale studies on ionic liquids. Chem. Rev. 2017, 117, 6636-6695. (d) Zhang, S.; Zhang, Q.; Zhang, Y.; Chen, Z.; Watanabe, M.; Deng, Y. Beyond solvents and electrolytes: Ionic liquids-based advanced functional materials. Prog. Mater. Sci. 2016, 77, 80-124. (e) Zhang, J.; Liu, H.; Jiang, L. Membrane-Based Strategy for Efficient Ionic Liquids/Water Separation Assisted by Superwettability. Adv. Funct. Mater. 2017, 27, 1606544.

(16) Ahmed, A. In Sustainable Organic Synthesis in Ionic Liquids; Inamuddin, A. A., Ed.; Applications of Nanotechnology for Green Synthesis. Nanotechnology in the Life Sciences; Springer: Cham, 2020.

(17) Alizadeh, A.; Khodaei, M. M.; Eshghi, A. Ambiphilic dual activation role of a task-specific ionic liquid: 2-hydroxyethylammonium formate as a recyclable promoter and medium for the green synthesis of $\beta$-Nitrostyrenes. J. Org. Chem. 2010, 75, 8295-8298.

(18) Bicak, N. A new ionic liquid: 2-hydroxy ethylammonium formate. J. Mol. Liq. 2005, 116, 15-18.

(19) Okukawa, T.; Suzuki, K.; Sekiya, M. Formic acid reduction. XX. Reduction of 2-Benzylidene-1,3-indandiones. Chem. Pharm. Bull. 1974, 22, 448-451. 